\title{
A study of gynecological profile of patients undergoing hysterectomy with special reference to its indications
}

\author{
Pujitha Devi Suraneni $^{1 *}$, Sradhanjali Maharana ${ }^{2}$
}

\begin{abstract}
${ }^{1}$ Department of Obstetrics and Gynecology, Malla Reddy Institute of Medical Sciences, Hyderabad, Telangana, India ${ }^{2}$ Consultant Gynecologist, Archana Hospital, Hyderabad, Telangana, India
\end{abstract}

Received: 15 June 2017

Accepted: 08 July 2017

\section{*Correspondence:}

Dr. Pujitha Devi Suraneni,

E-mail: suranenipujitha@yahoo.co.in

Copyright: () the author(s), publisher and licensee Medip Academy. This is an open-access article distributed under the terms of the Creative Commons Attribution Non-Commercial License, which permits unrestricted non-commercial use, distribution, and reproduction in any medium, provided the original work is properly cited.

\begin{abstract}
Background: Hysterectomy is the most frequently performed major gynecological surgical procedure, with millions of procedures performed annually throughout the world. Approximately $90 \%$ of hysterectomies are performed for benign conditions, such as fibroids causing abnormal uterine bleeding. Objective of the study was to study the gynecological profile of women undergoing hysterectomy.

Methods: In this study 60 cases of hysterectomy were analyzed over a period of 2 years who underwent hysterectomy at Department of Obstetrics and Gynecology, Chalmeda Anand Rao Institute of Medical Sciences, Karimnagar. Informed consent was taken from all women. Detailed history, complete clinical, gynecological examination was carried out.

Results: Maximum patients i.e. 56.7\% were in the age group of 41-50 years followed by the age of 31-40 years i.e. $33.3 \%$. Maximum number of hysterectomies were performed in Para 3. Maximum number of patients had menstrual problems which are about $63.3 \%$ and next more common complaint was discharge per vagina (53.3\%). Of the 60 cases that underwent hysterectomies $40 \%$ of them are for abnormal uterine bleeding, $30 \%$ of them are for uterine fibroid, $15 \%$ of them are for endometriosis, $8.3 \%$ of them are for adenomyosis, $6.6 \%$ of them are for cervical dysplasia.
\end{abstract}

Conclusions: The most common indication for hysterectomy was abnormal uterine bleeding.

Keywords: Complications, Sequel, Vaginal hysterectomy

\section{INTRODUCTION}

Hysterectomy is the most frequently performed major gynecological surgical procedure, with millions of procedures performed annually throughout the world. ${ }^{1}$

Approximately $90 \%$ of hysterectomies are performed for benign conditions, such as fibroids causing abnormal uterine bleeding. ${ }^{2}$

Suchuhardt of Germany in 1893 performed the $1^{\text {st }}$ extensive vaginal hysterectomy for cervical cancer. ${ }^{3}$ Werthiem refined the abdominal operation and the vaginal by schauta refined the vaginal operation. Noteworthy contributions were made to the techniques of gynecologic surgery by Sims, Werthiem, Sschauta, Kelly, Clarhe, Mayo, Meigs and many others.

Jacobaeus of Sweden in 1910 performed the first human laparoscopy by using pneumoperitoneum and a nipze cystoscope. ${ }^{4}$ Richardson 1929 in USA performed the first total abdominal hysterectomy to avoid discharge from the cervical remnant to avoid cervical stump carcinoma. Raoul palmer 1940 of France popularized gynecological laparoscopy and he is considered to be the father of modern gynecological approach, who also performed first 
human laparoscopic tubal fulguration in 1962. Kurt Semm 1984 in Germany first described a technique for laparoscopic assistance in vaginal hysterectomy. Harry Reich performed the first laparoscopic hysterectomy in January 1988. Since then laparoscopic assisted vaginal hysterectomy (LAVH) and classical abdominal SEMM (serrated edge macro morcellator) hysterectomy, LASH (laparoscopic supracervical hysterectomy) have evolved. ${ }^{5}$

The present has been undertaken to study the gynecological profile of patients undergoing hysterectomy.

\section{METHODS}

In this study 60 cases of hysterectomy were analyzed over a period of 2 years who underwent hysterectomy at Department of Obstetrics and Gynecology, Chalmeda Anand Rao Institute of Medical Sciences, Karimnagar. Name, Age, Address, Occupation, Socioeconomic status, Date of admission, Date of operation and Date of discharge were noted. Chief complaints, detail history of menstrual cycles, abnormalities of menstrual cycles like menorrhagia, polymenorrhea, metrorrhagia, postcoital bleeding, dyspaurenia, dysmenorrheal and postmenopausal bleeding were recorded.

History of any discharge per vagina and details of its quality, quantity, odor, color etc. were enquired into. History of bladder and bowel disturbances was asked. Histories of mass per vagina, chronic cough, backache, pain abdomen were asked. Histories of treatment taken for any previous ailments were recorded. In the past history, history of any medical illnesses like Hypertension, Diabetes Mellitus, Tuberculosis, Infections and Asthma were asked. Histories of any previous surgeries were enquired. In the family history, history of similar complaints in the family members, history of any genital or breast malignancies among the family members were asked. In the menstrual history, age of menarche, regularity of the cycles in the past and present, history of passing clots, number of pads used per day, dysmenorrheal and last menstrual period was asked.

In the obstetric history, age of marriage, parity, mode of deliveries, puerperal events, and duration since last delivery was asked. Histories of contraception or sterilization were asked. Detailed general and physical examination of the patients were carried out and the following were noted: built, nourishment, pallor, edema of feet, icterus, thyroid, breast, lymphadenopathy and varicose veins.

In abdominal examination, any palpable mass, organomegaly, tenderness, ascites, position of umbilicus, engorged veins and hernial sites were examined. Per speculum-condition of vagina and cervix, descent of cervix and any discharge are noted. In bimanual pelvic examination, position and mobility of uterus and fornices are noted.

\section{RESULTS}

Table 1: Age wise distribution of study subjects.

\begin{tabular}{|lll|}
\hline Age (years) & Number & $\%$ \\
\hline Up to 30 & 01 & 1.7 \\
\hline $31-40$ & 20 & 33.3 \\
\hline $41-50$ & 34 & 56.7 \\
\hline$>50$ & 05 & 8.3 \\
\hline Total & 60 & 100 \\
\hline
\end{tabular}

Table 1 shows the age wise distribution of patients. It is seen that maximum patients i.e. $56.7 \%$ were in the age group of 41-50 years followed by the age of 31-40 years i.e. $33.3 \%$.

Table 2: Parity wise distribution of study subjects.

\begin{tabular}{|lll|}
\hline Parity & Number & $\%$ \\
\hline Nullipara & 0 & 0 \\
\hline Para 1 & 2 & 3.4 \\
\hline Para 2 & 23 & 38.3 \\
\hline Para 3 & 32 & 53.3 \\
\hline Para 4 and above & 3 & 5 \\
\hline
\end{tabular}

It is noted that maximum number of hysterectomies were performed in Para 3 which is about $53.3 \%$ followed by Para 2 which is about $38.3 \%$. In this study, none of the nulliparous women underwent hysterectomy.

Table 3: Distribution of study subjects as per their complaints.

\begin{tabular}{|lll|}
\hline Complaints & Number & $\%$ \\
\hline Abnormal menstrual flow & 38 & 63.3 \\
\hline White discharge per vagina & 32 & 53.3 \\
\hline Pain abdomen & 11 & 18.3 \\
\hline Postmenopausal bleeding & 0 & 0 \\
\hline Dysmenorrhea & 12 & 20 \\
\hline Backache & 12 & 20 \\
\hline Dyspaurenia & 0 & 0 \\
\hline Urinary disturbances & 4 & 6.6 \\
\hline General weakness & 22 & 3.6 \\
\hline
\end{tabular}

Maximum number of patients had menstrual problems which are about $63.3 \%$ and next more common complaint was discharge per vagina $(53.3 \%)$.

Table 4: Distribution according to the indication for hysterectomy.

\begin{tabular}{|lll|}
\hline Indication & No. of cases & $\%$ \\
\hline A U B & 24 & 40 \\
\hline Uterine fibroids & 18 & 30 \\
\hline Endometriosis & 9 & 15 \\
\hline Adenomyosis & 5 & 8.3 \\
\hline Cervical dysplasia & 4 & 6.6 \\
\hline
\end{tabular}


Of the 60 cases that underwent hysterectomies $40 \%$ of them are for AUB, 30\% of them are for uterine fibroid, $15 \%$ of them are for endometriosis, $8.3 \%$ of them are for adenomyosis, $6.6 \%$ of them are for cervical dysplasia. Among AUB cases most of them underwent vaginal hysterectomy (45.8\%), among uterine fibroid cases most of them underwent abdominal hysterectomy (44.4\%), among endometriosis cases most of the cases underwent laparoscopic hysterectomy $(26.6 \%)$, among adenomyosis cases $2(40 \%)$ underwent abdominal hysterectomy and 2 $(40 \%)$ vaginal hysterectomy and among cervical dysplasia cases $2(50 \%)$ cases underwent abdominal hysterectomy and $2(50 \%)$ cases underwent vaginal hysterectomy.

Table 5: Pre-operative medical complications recorded in the study subjects.

\begin{tabular}{|lllll|}
\hline Disease & Abdominal & Vaginal & LA VH & $\%$ \\
\hline Anemia & 6 & 4 & 0 & 16.6 \\
\hline Hypertension & 5 & 8 & 1 & 21.6 \\
\hline Hypothyroidism & 0 & 1 & 0 & 1.6 \\
\hline cardiac changes & 0 & 1 & 0 & 1.6 \\
\hline Diabetes & 0 & 0 & 0 & 0 \\
\hline Asthma & 0 & 0 & 0 & 0 \\
\hline
\end{tabular}

Of the 60 cases studied anemia was present in 10 patients $(16.6 \%)$. Of these 2 patients had severe anemia and were given preoperatively blood transfusion. Remaining 8 patients had borderline anemia and they were given iron supplementation and high protein diet to improve general condition.

Hypertension was found in 14 patients $(21.6 \%)$ in this study. Among these 5 patients underwent abdominal hysterectomy, 8 patients underwent vaginal hysterectomy and 1 patient underwent LAVH.

\section{DISCUSSION}

Maximum number of hysterectomies was performed in women in age group of 41-50 years $(56.6 \%)$ and least in age group of $21-30$ years $(1.8 \%)$. Rubina et al 2005 observed similar incidence of $79.7 \%, 45.2 \%$ and $45.2 \%$ hysterectomies in 41-50 years age group respectively. ${ }^{6}$ Amirika et al observed similar incidence of $73 \%$ of hysterectomies in 31-50 years age group and 37\% in 4150 years age group. ${ }^{7}$ Present study shows that least number of hysterectomies were performed in age group of 21-30 years (1.8\%) followed by 51 years and above age group $(8.3 \%)$.

Present study shows maximum number of hysterectomies were performed in Para 3 (53.3\%), followed by Para 2 $(38.3 \%)$ and nil $(0 \%)$ in nulliparous women. Majority of Para 3 women underwent vaginal hysterectomy. Majority of Para 2 women underwent laparoscopic assisted vaginal hysterectomy. Vaginal hysterectomy is preferred in highly parous women because the perineum is lax and vaginal hysterectomy is easier in this woman but
Nulliparity is no way a contraindication to vaginal hysterectomy. Dickers et al and Garry et al has reported higher incidence of hysterectomies in parous women $(75.5 \%, 90.3 \%, 93 \%$ respectively) where as in nulliparous it was $90.7 \%, 9.7 \%$, and $7 \%$ respectively. ${ }^{8,9}$

Emil et al, Garry et al have also reported abnormal menstrual flow as commonest symptom as $41.4 \%, 43.2 \%$ and $71.9 \%$ respectively. ${ }^{10,9}$ Present study showed that the next common symptom is white discharge which was $53.3 \%$. Emil et al observed white discharge in $0.9 \%$, $16 \%, 3.6 \%$ and $13 \%$ respectively. ${ }^{10}$ Present study showed that the pain abdomen was observed in $18.3 \%$.

Of the 60 cases that underwent hysterectomies $40 \%$ of them are for AUB, $30 \%$ of them are for uterine fibroid, $15 \%$ of them are for endometriosis, $8.3 \%$ of them are for adenomyosis, $6.6 \%$ of them are for cervical dysplasia. Among AUB cases most of them underwent vaginal hysterectomy (22.5), among uterine fibroid cases most of them underwent abdominal hysterectomy (23.3\%), among endometriosis cases most of the cases underwent laparoscopic hysterectomy (26.6\%), among adenomyosis cases most of them underwent vaginal hysterectomy $(36.14 \%)$ and among cervical dysplasia cases 2 cases underwent abdominal hysterectomy and 2 cases underwent vaginal hysterectomy.

Obese patients are likely to have hypertension, diabetes etc. Intra operative and postoperative blood loss is more in these women. In this group of women or laparoscopic assisted vaginal hysterectomy was more preferred. There is an increased incidence of delayed wound healing, increased wound infection in these people. Hence abdominal route was not preferred in this group of patients.

Pitkin RM 1976 observed morbidity in the form of fever and increased blood loss during surgery were observed in obese patients. In this series 2 patients were obese who underwent vaginal hysterectomy without untoward effects. ${ }^{11}$ Garry et al in 2004 observed more number of major complications in obese patients. ${ }^{9}$

\section{CONCLUSION}

The most common indication for hysterectomy was abnormal uterine bleeding. Maximum number of hysterectomies were performed in Para $3(53.3 \%)$, followed by Para $2(38.3 \%)$ and nil $(0 \%)$ in nulliparous women. Majority of Para 3 women underwent vaginal hysterectomy. Majority of Para 2 women underwent laparoscopic assisted vaginal hysterectomy. Vaginal hysterectomy is preferred in highly parous women.

\section{Funding: No funding sources \\ Conflict of interest: None declared}

Ethical approval: The study was approved by the Institutional Ethics Committee 


\section{REFERENCES}

1. Garry R. Health economics of hysterectomy. Best Pract Res Clin Obstet Gynaecol. 2005;19(3):451-65.

2. Flory N, Bissonette F, Birik YM. Psychosocial effects of hysterectomy: literature review J Psychosom Res. 2005;59(3):117-29.

3. Sutton C. Hysterectomy: A historical perspective. Baill Clin Obstet Gynaecol. 1997;11:1-22.

4. Munro MG, Deprest J. laparoscopic hysterectomy. Does it work? A bicontinental review of the literature and clinical Commentary. Clin Obstet Gynaecol. 1995;2:401-25.

5. Reich H, Decaprio J, McGlynn F. Laproscopic hysterectomy J Gynecol Surg. 1989;5:213-6.

6. Rubina B, Parveen Z, Sulthana R, Khan BA. Two year audit of complications of hysterectomy at Auyb Medical College, Abottabad. 2005;17(2):47-9.

7. Amirikia H, Evans TN. Ten year review of hysterectomies: trends, indications, and risks. Am J Obstet Gynecol. 1979;134(4):431-7.

8. Dicker RC, Scally MJ, Greenspan JR, Layde PM, Ory HW, Maze JM et al. Hysterectomy among women of reproductive age. Trends in the United States, 1970-1978. J Am Med Asso. 1982;248(3):323-7.

9. Garry R, Fountain J, Mason S, Hawe J, Napp V, Abbott $\mathbf{J}$ et al. The eVALuate study: two parallel randomised trials, one comparing laparoscopic with abdominal hysterectomy, the other comparing laparoscopic with vaginal hysterectomy. Br Med J. 2004;328(7432):129.

10. Emil F Cava, Willis M Russel. Intramural pregnancy with uterine rupture. A case report. Am J Obstet Gynecol. 1978;131(2):214-6.

11. Pitkin RM. Abdominal hysterectomy in obese women. Surg Gynecol Obstet. 1976;142(4):532-36.

Cite this article as: Suraneni PD, Maharana S. A study of gynecological profile of patients undergoing hysterectomy with special reference to its indications. Int J Reprod Contracept Obstet Gynecol 2017;6: 3651-4. 